\title{
AUTORIDADE, DISCIPLINA E APLICAÇÃO DE CASTIGOS NAS REPRESENTAÇÕES DE PROFESSORES (1910-1930) ${ }^{1}$
}

DOI: http://dx.doi.org/10.1590/2236-3459/68029

\author{
Geisa Magela Veloso \\ Universidade Estadual de Montes Claros, Brasil.
}

Rafael Baioni do Nascimento

Universidade Estadual de Montes Claros, Brasil.

Mônica Maria Teixeira Amorim

Universidade Estadual de Montes Claros, Brasil.

\section{$\cos 8$}

\begin{abstract}
Resumo
O estudo situa-se no campo da História Cultural, na vertente defendida por Chartier (1990), e tem por objetivo discutir representações sobre as práticas disciplinares, por compreender que a disciplina se constitui como uma das finalidades da escola que, para além da instrução, também precisa educar as crianças. A discussão apóia-se em diferentes fontes, quais sejam - documentos oficiais do Governo de Minas Gerais e jornais publicados em Montes Claros/MG, sendo que o recorte temporal incluiu as décadas de 1910 a 1930. Nesse período, observou-se um deslocamento nas representações dos professores - de uma contraposição intuitiva da disciplina baseada em castigos para um discurso propriamente científico, que sinaliza a sua abolição e a defesa do equilíbrio entre autoridade e liberdade, com base na Escola Nova. Palavras-chave: história da educação, disciplina, liberdade e autoridade, castigos e punições.
\end{abstract}

\section{AUTHORITY, DISCIPLINE AND PUNISHMENT'S APPLICATION IN THE TEACHER REPRESENTATIONS} (1910-1930)

\section{Abstract}

The study is located in the field of cultural history, into the perspective defended by Chartier (1990), and aims to discuss representations of disciplinary practices to understand that discipline is constituted as one of the school purposes that, in addition to instruction, also need to educate children. The discussion leans on different sources - official documents of the Government of Minas Gerais and newspapers published in

\footnotetext{
${ }^{1}$ A pesquisa contou com apoio financeiro da Fundação de Amparo à Pesquisa do Estado de Minas Gerais Fapemig. O projeto de pesquisa foi aprovado pelo Comitê de Ética da Unimontes, sob parecer 2522, em conformidade com a Resolução 196/96, do Conselho Nacional de Saúde.
} 
Montes Claros / MG, and the time frame included the 1910s to 1930. During this period, there was a change in the representation of teachers - an intuitive contrast of discipline based on punishments for proper scientific discourse, which signals its abolition and defense of the balance between authority and freedom, based on the New School.

Keywords: history of education, discipline, freedom and authority, punishments and penalties.

\section{AUTORIDAD, DISCIPLINA Y APLICACIÓN DE CASTIGOS EN LAS CREENCIAS DE PROFESORES} (1910-1930)

\section{Resumen}

El estudio se sitúa em el campo de la historia cultural, en la vertiente defendida por Chartier (1990), y objetiva discutir crencias sobre las prácticas disciplinares, por comprender que la disciplina se constituye una de las finalidades de la escuela que, además de la instrucción, también necesita educar a los niños. La discusión se basa en diferentes fuentes - documentos oficiales del Gobierno de Minas Gerais y periódicos publicados em la ciudad de Montes Claros, provincia de Minas Gerais, Brasil, considerándose las décadas de 1910 hasta 1930. En ese período, se observó un desplazamiento en las representaciones de los professores - de una contraposición intuitiva de la disciplina basada em castigos para un discurso propriamente científico, que señala su abolición y la defensa del equilibrio entre autoridad e libertad, con base en lo que se costumbra llamar en Brasil de Escola Nova.

Palabras clave: historia de la educación, disciplina, libertad y autoridad, castigos e punições.

\section{AUTORITÉ, DISCIPLINE ET L'APPLICATION DES PUNITIONS DANS LES REPRÉSENTATIONS DE PROFESSEURS (1910-1930)}

\section{Résumé}

L'étude se situe dans le champ de l'histoire culturelle, du point de vue défendu par Chartier (1990), et vise à discuter des représentations des pratiques disciplinaires, en comprenant que la discipline est constituée comme l'une des finalités de l'école qui, au-delà de l'instruction a également pour objectif d'éduquer les enfants. La discussion se fonde sur des différentes sources - les documents officiels du gouvernement du Minas Gerais et des journaux publiés dans Montes Claros / MG publiés dans les années 1910 à 1930. Au cours de cette période, il s'est observé un changement dans les représentations des enseignants - d'une contre-position intuitive de la discipline basée sur la punition pour un discours scientifique à proprement parlé, qui signale son abolition et la défense de l'équilibre entre l'autorité et la liberté, basé sur l'Éducation Nouvelle.

Mots-clés: histoire de l'éducation, discipline, liberté et autorité, corrections et punitions. 


\section{Introdução}

pesquisa situa-se no âmbito da História da Educação, tem a disciplina ${ }^{2}$
como objeto de estudo e orientou-se pela História Cultural, na vertente
defendida por Chartier (1990), que propôs os conceitos de representações, apropriações e práticas como ferramentas para a reconstituição da memória coletiva.

Para Chartier (1990, p. 19), as representações "traduzem posições e interesses objectivamente confrontados e que, paralelamente, descrevem a sociedade tal como pensam que ela é, ou mesmo como gostariam que fosse" e, embora aspirem à universalidade, são determinadas por interesses dos grupos sociais que as forjam. Ao discutir o processo de produção de representações, o autor considera ser importante conferir atenção especial às forças que atuam no mundo social e aos processos que determinam as operações de construção do sentido. Isso significa reconhecer que as inteligências não são desencarnadas e que as categorias, aparentemente mais variáveis, devem ser construídas na descontinuidade das trajetórias históricas.

Ao discutir a pertinência operatória de se tomar o conceito de representação para estudar objetos culturais no âmbito da historiografia, Chartier $(1990,2002)$ apresenta duas ordens de razões que a justificam. Em primeiro lugar, o fato de o conceito não ser estranho às sociedades do Antigo Regime, cuja utilização manifesta a tensão entre duas famílias de sentido: a representação como dando a ver uma coisa ausente, o que pressupõe uma distinção radical entre aquilo que representa e aquilo que é representado; a representação como a exibição de uma presença, apresentação pública de algo ou de alguém.

A segunda razão é que, mais do que um conceito de mentalidade, as representações permitem articular três modalidades de relações com o mundo social: a) 0 trabalho de classificação e de delimitação que produz configurações intelectuais múltiplas, através das quais a realidade é contraditoriamente construída; b) as práticas que visam fazer reconhecer uma identidade social, exibir uma maneira própria de estar no mundo, significar simbolicamente um estatuto e uma posição; c) as formas institucionalizadas e objetivadas pelas quais alguns "representantes" marcam a existência do grupo, da classe, da comunidade (CHARTIER, 2002). Por essa orientação, discutimos representações de disciplina produzidas por professores e outros profissionais da educação, por um processo em que a reconstituição de facetas da história se processou pela crença de que as representações não são "a verdade" sobre os acontecimentos, mas dão a ver a realidade, podendo se constituir como sentimentos, percepções, expectativas, saberes e crenças dos sujeitos (CHARTIER, 1990).

Tal perspectiva implica reconhecer que as representações analisadas neste artigo não são a "verdade" sobre as práticas disciplinares. Também não podem ser vistas como meras produções individuais - os posicionamentos representam um grupo profissional, uma classe, uma comunidade situada em um determinado tempo histórico. Assim, o

2 Chervel (1990) considera que, no âmbito das ciências da educação, a noção de disciplina pode ser compreendida como "matérias" ou "conteúdos" de ensino, sendo este um termo ausente de todos os dicionários do século XIX. Para o autor, até essa época, em seu uso escolar, o termo "disciplina" e a expressão "disciplina escolar" designavam a vigilância dos estabelecimentos, a repressão das condutas prejudiciais à sua boa ordem e aquela parte da educação dos alunos que contribui para isso. No âmbito deste artigo, é este o sentido com o qual trabalhamos, ao utilizar a expressão "disciplina escolar". 
objetivo do estudo é discutir representações sobre as práticas disciplinares, por compreender que a disciplina se constitui como uma das finalidades da escola que, para além da instrução, também precisa educar as crianças.

Com Chervel (1990), consideramos que a escola trabalha com finalidades de diferentes ordens, como as finalidades religiosas, culturais, sócio-políticas e de ordem psicológica. Para o autor, uma parte das finalidades da escola relaciona-se à instrução e ao trabalho com as disciplinas curriculares. Mas, de outra parte, a escola também se responsabiliza pela educação, sendo que os próprios conteúdos da instrução são colocados a serviço desta finalidade; e, assim, assume finalidades mais sutis de socialização, visando à aprendizagem da ordem social, da higiene, da polidez, da disciplina, dos comportamentos então estabelecidos como decentes etc.

O trabalho de Foucault (2014), ainda que sob outra perspectiva teórica, também aponta nessa direção, de se considerar a realidade como um jogo de forças, e de se pensar a escola e a educação não apenas como uma instituição de transmissão de conhecimento, mas também como um dos vários lugares em nossa sociedade em que as subjetividades são constituídas - isto é, constituídas de acordo com determinados dispositivos e estratégias de poder, algumas delas contraditórias e conflitantes. Segundo ele: "a 'disciplina' não pode se identificar com uma instituição nem com um aparelho; ela é um tipo de poder, uma modalidade para exercê-lo, que comporta todo um conjunto de instrumentos, de técnicas, de procedimentos, de níveis de aplicação, de alvos" (2014, p. 208), e, portanto, não se limita à escola (ou à prisão e ao hospital), mas perpassa todo o tecido social de diversas maneiras, na família, na política, na ciência, na religião etc. Essa amplitude da função disciplinar fica bem evidente no material analisado nesse artigo, no decorrer do qual se pode observar como os discursos da religião, da filosofia e das ciências foram invocados para balizar determinadas práticas disciplinares na escola em Minas Gerais das décadas de 1910 a 1930.

Em nosso estudo foram utilizadas diferentes fontes documentais para acesso ao passado - correspondência oficial, relatório de inspeção técnica e publicações dos jornais montes-clarenses Gazeta do Norte, Montes Claros e A Ordem. O jornal Gazeta do Norte é um semanário publicado em Montes Claros, entre os anos de 1918 e 1962, que empreendeu campanhas educativas, disseminou ideias e práticas, denunciou problemas. O jornal $A$ Ordem é um semanário publicado em Montes Claros nas primeiras décadas do século XX, que também revelou finalidades educativas em relação ao seu público. $O$ jornal Montes Claros é um semanário, publicado entre os anos de 1916 e 1917 que, igualmente, revelou preocupações com o desenvolvimento da cidade, dedicando espaço para questões relacionadas com a educação.

A correspondência oficial utilizada refere-se a uma manifestação de protesto de Christina Vitalina dos Santos ${ }^{3}$, endereçada ao Secretário do Interior do estado de Minas Gerais, contra o termo de visita de inspeção técnica feita por Herculino Pereira de Sousa ${ }^{4}$,

\footnotetext{
${ }^{3}$ Christina Vitalina dos Santos uma professora primária da Escola Masculina do Bairro Malhada, localizada na cidade de Montes Claros/MG. No ano de 1913, época em que foram registradas as ocorrências que tomamos como referência nesse artigo, a professora contava com 30 anos de exercício docente.

${ }^{4}$ Herculino Pereira de Sousa era advogado, exercendo diferentes ofícios, dentre eles a de promotor de justiça da Comarca de Montes Claros, a de inspetor técnico do ensino, a professor e de vice-diretor da Escola Normal Norte Mineira. Também exerceu ofício de jornalista, responsável pela coluna Horas Vagas, no jornal Montes Claros.
} 
no dia 12 de abril de 1913. Também consultamos um relatório de inspeção do referido inspetor, referente ao trabalho realizado em 1913, datado de 30 de janeiro de 1914.

Para captar a sincronia do movimento histórico local, com discussões mais amplas, foi tomada a Revista do Ensino-MG, publicação da Inspetoria da Instrução do Estado de Minas Gerais, que disseminou princípios educativos inscritos no projeto de reforma pretendido para as escolas mineiras.

O recorte temporal definiu-se pelas décadas de 1910 a 1930 - período marcado por uma série de mudanças políticas, educacionais, culturais, comportamentais e tecnológicas. No campo educacional, por influência da Escola Nova, questiona-se a educação escolar tradicional, pautada em rígida disciplina e em castigos impostos aos alunos (LIBÂNEO, 1994; GADOTTI, 1997; MIZUKAMI, 1986). O ideário da escola nova, que tem suas raízes na concepção humanista de educação proposta por Jean Jacques Rousseau (1712-1788), ancora-se na renovação dos saberes e práticas para educar a criança, produzir a civilização e a modernidade. Esse ideário encontrou no Brasil o apoio de educadores como Anísio Teixeira, Fernando de Azevedo, Florestan Fernandes, Lourenço Filho, entre outros.

Para Lourenço Filho (1978), as primeiras instituições escolanovistas surgem na Europa, no final do século XIX, sendo que a expressão Escola Nova não pode ser compreendida como um tipo particular de escola, mas um conjunto de princípios e a uma multiplicidade de práticas, que visavam à revisão de formas tradicionais de ensino e à solução de problemas educacionais pela aplicação da ciência. No Brasil, diferentes correntes de pensamento também coexistiram no interior desse movimento.

Em Minas Gerais, a adoção de princípios da Escola Nova foi institucionalizada pela Reforma Francisco Campos (1927), que disseminou os ideais renovadores a partir de uma série de aparatos: criação da Escola de Aperfeiçoamento em Belo Horizonte, além de 21 escolas normais oficiais no interior do estado; promoção de cursos e palestras, instalação de bibliotecas escolares; intensificação da divulgação da Revista do Ensino.

No âmbito da cidade de Montes Claros, os últimos anos da década de 1920, mas, sobretudo, a década de 1930 é um período de grande efervescência cultural, em que sua Escola Normal assume a tarefa de formar professores, também, desenvolvendo ações para educar a população. Neste bojo, o jornal Gazeta do Norte chama as famílias a participar do debate, publica artigos e o conteúdo de conferências pedagógicas, com a intenção de educar os montes-clarenses, forjando o cidadão moderno e civilizado.

Neste contexto, o presente artigo discute representações de sujeitos da educação, na cidade de Montes Claros/MG, a partir de suas 3 seções. Na primeira, a discussão gira em torno de disputas por autoridade, disciplina e aplicação de castigos. $O$ recorte situa-se em período anterior à década de 1920, em que há uma contraposição intuitiva à disciplina baseada em castigos (caso de Christina Vitalina dos Santos). Na segunda seção, situada na década de 1920, o discurso ambíguo indica a abolição dos castigos, por um lado, e a tentativa de defesa da tradição religiosa, por outro (caso de José Lúcio dos Santos). Por fim, na terceira e última seção, a discussão situa-se na década de 1930, em que o discurso propriamente científico sinaliza a abolição dos castigos e a defesa do equilíbrio entre autoridade e liberdade com base na Escola Nova (caso de José Raymundo Netto). 


\section{Autoridade e disciplina da década de 1910 - uma contraposição intuitiva aos castigos e punições}

No contexto da cidade de Montes Claros, entre as décadas de 1910 e 1930, mapeamos representações sobre educação, disciplina e aplicação de castigos, bem como orientações destinadas a pais e educadores. Tais representações visavam produzir a modernização, a civilização, o desenvolvimento e o progresso. Com Chartier (1990), compreendemos as representações como práticas de ordenamento do social, construídas pelos indivíduos, enquanto sujeitos sociais, que buscam compreender a realidade na qual estão inseridos e travam relações. O autor entende que as estruturas do mundo social não são um dado objetivo; são historicamente produzidas e inscritas nas práticas complexas, múltiplas e diferenciadas, que se articulam e constroem o mundo como representação.

Por esta perspectiva, ao analisar os anos de 1910, as representações disseminadas nos jornais tomados como fontes revelam inquietação com a precariedade da estrutura e organização da rede de escolas, nela incluindo a Escola Normal de Montes Claros, que fora reinstalada no ano de 1915. As publicações também revelam uma preocupação com a qualidade do trabalho desenvolvido pelos professores, bem como uma defesa da parceria escola-família para a educação.

Em publicações do inspetor Herculino Pereira de Sousa, no Jornal Montes Claros, no ano de 1916, são destacadas falhas do sistema educacional, mas, também os erros dos pais, que delegavam toda a responsabilidade de educação à escola.

\footnotetext{
A escola é, cada vez mais, o centro de convergência das nossas preoccupações. Tudo se espera da escola. Exagera-se até a influência e a importância da escola, como se ella, só ella, podesse ser a fonte de tudo.

[...] Infelizmente, entre nós, ainda que parece, bem longe estamos d'esse interesse dos progenitores pelo ensino dos filhos.

Há muitos paes que de tudo cuidam, tudo pensam e a tudo provêm, mas, deixam transcorrer annos inteiros sem cogitar si o ensino de seus filhos é o mais conveniente ou mesmo si elles recebem na escola algum ensino. Preparemo-nos, porém, para melhores tempos; e os maus professores que ponham as barbas de môlho... (SOUSA, 26 de outubro de 1916a, p. 02)
}

Ainda no Jornal Montes Claros, Herculino Pereira de Sousa manifestou interesse pela qualidade da educação escolar, pelo compromisso e competência dos professores, pelo desempenho e comportamento dos alunos.

De nada vale um diploma mais ou menos vistoso e sem corresponder ao approveitamento real do alumno.

São velhas estas verdades, mas precisam ser sempre repetidas.

Por minha parte quero convencionalmente pertencer à classe dos professores exigentes, sem sahir dos limites da justiça.

A benevolência excessiva, sempre prompta ao lissez faire, laissez auler, colloco os seus adeptos mais próximos de certas tendências da época, porem, mui longe do bom senso e do nosso interesse real e palpitante. (SOUSA, 30 de novembro de 1916b, p. 02)

É neste contexto de críticas à educação, que situamos episódio relacionado à disciplina escolar, protagonizado por uma professora primária, Christina Vitalina dos Santos, e o inspetor do ensino Herculino Pereira de Sousa. Em correspondência redigida pela professora ao Secretário do Interior do Estado de Minas Gerais, no ano de 1913, foi 
possível captar uma intensa discussão relativa à educação escolar e sua função regeneradora e civilizatória.

A professora mostra-se indignada com a avaliação que o referido inspetor houvera exarado sobre sua competência no exercício da função docente, sendo que a argumentação girou em torno da aplicação de castigos, da disciplina e da autoridade do professor. O embate originou-se de visita de técnica à Escola Masculina do Bairro Malhada, em que o inspetor do ensino presenciou o desfecho de um episódio em que a professora Christina Vitalina dos Santos aplicara castigo a alguns de seus alunos. No depoimento:

Tendo 3 alumnos se retirado da escola, enquanto leccionava a $2^{\circ}$ ano, e eu notando a falta, e sendo também avisada de que eles se achavam jogando bolinhas, mandei-os chamar, e em castigo, a desobediência as regras do Programma e da escola, expulsei-os por aquelle dia dos trabalhos escolares, coincidindo com a chegada do Sr. Inspector Dr. Herculino, ao qual fiz-lhe sciente de todo o ocorrido.

Entrando depois na escola um dos expulsos, o Sr. Dr. exprobou-Ihe o seu erro confirmando o meu acto; porem o menino desfez-se em choros, mas nem por isto eu me demovia em retroceder a sentença dada; e mesmo que, por defferencia ao Sr. Inspector, abrandei um pouco, esperando também a sua opinião resolutiva sobre a acção (SANTOS, 24 de abril de 1913).

Para a professora, o inspetor a avaliara negativamente dado o fato de que tenha "abrandado" suas atitudes com o menino que houvera sido castigado e, por isso, constrói sua argumentação alicerçada nesta temática. Por sua vez, o inspetor Herculino Pereira de Sousa afirma que sua avaliação negativa não se deveu a este fato isolado, mas, a um conjunto de elementos, também relacionados com a frequência dos alunos às aulas e aos resultados nos exames escolares. Ao manifestar-se sobre as queixas da professora, o inspetor reafirma sua avaliação e arremata: "a professora tem interpretado mal a minha franqueza" (SOUSA, 30 de janeiro de 1914). E ainda acrescenta:

Com pesar, porém, com a sincera franqueza que me distinguem, devo dizer que esta escola esteve num verdadeiro desmantelo. Nenhuma ordem, nenhuma disciplina, nenhum horário, insignificante aproveitamento. [...] É pena que o governo não mande abrir inquérito sobre isto, por funccionario de sua confiança, afim de se apurar a verdade do estado da escola e dos termos de visita do inspector. Deixe-me dizer a franqueza inteira, digo a verdade inteira: taes funccionarios estão acostumados à inspecção proformula, aos inspectores de vistas gordas; ou, peior do que isso, a uma reles bajulação mentirosa, eis o motivo do abespinhamento. Isto, porém, não me incommoda. Lamento somente o estado do ensino na escola e nada mais (SOUSA, 30 de janeiro de 1914 - grifos no original).

Conforme o inspetor, no ano de 1913, a comissão examinadora dera-lhe "[...] as peiores informações do resultado verificado nas provas finaes, o que era de esperar. Até aqui os exames faziam-se em família, e tudo se arranjava". O inspetor informa que, quando da aplicação das provas, compareceram 41 e faltaram 85 alunos. No entanto, apenas 10 foram aprovados, sendo 01 aluno aprovado com distinção e os demais 31 considerados como não preparados. Sobre a matrícula e a freqüência informa que, no ano de 1913, visitara a escola nos dias 12 de abril, 19 de maio e 17 de outubro de 1913, oportunidade em que estiveram presentes 56, 54 e 41 alunos, dentre os 119 matriculados no $1^{\circ}$ semestre e os 126 matriculados no $2^{\circ}$ semestre letivo (SOUSA, 30 de janeiro de 
1914).

Em defesa de sua perspectiva, a professora argumenta que, no dia da visita do inspetor, estavam presentes 54 alunos, número que considera elevado, posto que fosse "dia de feira, em que os meninos falham em quasi todas as escolas". Ainda segundo a professora, os seus alunos, em sua maior parte, eram "[...] pobres, e filhos de homens que carecem de suas cooperações neste dia [...]" (SANTOS, 24 de abril de 1913). A professora entende que o alto número de matrículas na escola era indicativo da confiança dos pais, do reconhecimento da sua autoridade e capacidade de educar.

\footnotetext{
Uma professora que vai perdendo a autoridade perante seus alumnos, perde muito mais ante os seus pais que são os primeiros a ter disto conhecimento. Como combinar-se o $\mathrm{n}^{\circ}$ tão alto da matricula - 119 -, uma frequencia relativa a mesma, com o termo lavrado pelo inspector? (SANTOS, 24 de abril de 1913)
}

Ainda em sua defesa, a professora se ressente da educação recebida pelas crianças no ambiente doméstico, que considerava falha e sobrecarregava a escola, que além de instruir, também precisava educar, inculcar valores morais e comportamentais. Conforme a professora, seus alunos chegavam à escola sem noção de valores e comportamentos adequados ao ambiente social.

A maior parte dos alumnos que actualmente fazem parte da minha escola, tem vindo sem noção alguma de educação domestica, e eu com os dados que a pratica tem me fornecido, tenho-os empregado, vendo afinal a transformação em muitos. O que vai fazer um professor ou professora numa escola? Vai ensinar! O que se depreende deste ensino? O alumno vai ali naquele centro beber e colher illustrações para o seu espirito, cujo desempenho a vida pratica tanto necessita, assim como para a sua alma, porque sem o preparo desta, aquella será inteiramente selvagem em seus costumes, o professor poderá sempre usar da sua autoridade e energia? (SANTOS, 24 de abril de 1913)

O que se observa é que o discurso da professora Christina interpela a educação recebida em casa, reiterando argumentos de Cunha (2003). O autor lembra que escola e família são instituições sociais que gravitam em torno de um mesmo centro, o indivíduo educável, sendo que ambas se encontram imbuídas da missão de conduzir as pessoas para um espaço futuro, supostamente melhor, mais desejável e superior. No entanto, ao longo de sua evolução, a escola foi se erguendo contra a família, na medida em que questionava a educação oferecida no lar e colocava a instituição escolar como espaço ideal para educar, por orientar-se pela ciência. Assim, desde a $2^{\underline{a}}$ metade do século XIX, a instituição familiar passou a ser apontada por seu mau funcionamento, caracterizada como incompetente, incapaz, sem qualidades para educar as crianças. $O$ discurso da ciência que orientava a escola, ao mesmo tempo, desqualificava a família na educação do corpo e do espírito (CUNHA, 2003).

No contexto montes-clarense, a professora Christina lembra que um professor está investido da autoridade inerente ao seu cargo, que este é uma pessoa competentemente apta para educar, ao contrário dos pais, que não orientavam adequadamente os seus filhos. Para a professora, autoridade e energia eram duas características essenciais na sala de aula, que deveriam estar associadas ao afeto do professor pelas crianças. 
Ellas [autoridade e energia] não faltam ao professor bem preparado, porem ninguém mais do que ele é conhecedor destas qualidades. É justamente quando o alumno pratica erros, que para muitos parece imperdoáveis, que o professor tira dahi lições de moral, de perdão, de bondade e de caridade, para lhe transmittir. Se todos os professores fossem usando da autoridade de que são investidos applicalas por qualquer inobservância as leis escolares, ficaria brevemente com a escola vazia. O que é o professor? É uma pessoa competentemente apta para lidar com as naturezas infantis. As escolas estão formadas e mantidas. Serão o esforço e o trabalho do professor ou do Inspector? Qual dos dous há concorrido para sua constituição, engrandecimento e manutenção? É o professor tão somente. O bom professor não carece de estimulo, elle por si já se constitue. Quais são os alicerces que o professor se arrima para galgar ao nível do conceito publico? São os alumnos com os seus preparos. Assim, se o professor não souber usar destes elementos que são a fonte donde hade tirar a sua elevação, empregando meios brandos e suaves, como hade conseguil-o com acções severas? As feras domesticam por meio de carinhos! Qual a criança que se não domará recebendo constantemente o influxo de acções bondosas e meigas? (SANTOS, 24 de abril de 1913)

Apesar de ter utilizado o castigo de suspensão de aulas a três de seus alunos que haviam infringido regras da escola, a professora Christina afirma a crença no poder do afeto nas relações com o aluno - houvera abrandado diante do choro de um dos garotos castigados -, por acreditar que a escola deveria acolher os alunos e educá-los. E, assim, tece críticas à utilização de meios opressivos e violentos, destacando os males que poderiam advir de seu uso.

Um menino insubordinado em uma escola, recebe por isto castigos, e... expulsão. Vai a outra, o mesmo. Assim, sucessivamente em todas. O que se póde esperar de uma criatura repudiada dos centros donde the poderia aderir algum bem? Exclusivamente, o mal. Pois, se as escolas são as portas que dão passagem a todas as classes que requerem guia para o bom encaminhamento de nossa vida, como havemos de fechal-as aos desvalidos do saber??

É mesmo as crianças mais bravias que o professor poderá melhor demonstrar a sua magia professional. Uma escola enche-se de naturezas divergentes umas das outras: umas, propendem para o fim a que ella é destinada, algumas affastam-se mais; outras, são inteiramente oppostas. O professor com a táctica que possue, auxiliado com o tempo, e os seus predicados, vê, em pouco tempo, aquelles mais indomáveis, marchar na mesma linha trajectoria que soube traçar. Quantas escolas não há afastado tantos criminosos? Quantos males ellas não têm evitado? Quantos amigos ellas não tem constituído? (SANTOS, 24 de abril de 1913)

Em suas representações, a professora Christina Vitalina Santos remete-nos a posicionamentos deste período histórico, que tomam a escolarização como motor de mudanças. Tais mudanças correlacionavam, positivamente, educação, progresso, civilidade e cidadania, sendo que, ao analfabetismo, era tributada uma série de problemas, como o ócio, os crimes e a marginalidade. Graff (1994) afirma que, desde a primeira metade do século XIX, a educação, nos dois lados do Atlântico, tornou-se uma obsessão vitoriana, uma estratégia de modernização e um remédio para as mudanças, sendo esta uma visão que enfatizava os objetivos sociais agregados à educação:

[...] a redução do crime e da desordem, a assimilação de valores morais (e protestantes) e, em uma extensão mais limitada, a ampliação da produtividade econômica ao invés de objetivos individualistas de desenvolvimento intelectual e avanço pessoal (GRAFF, 1994, p. 67).

Por essa inteligibilidade foi produzida uma representação da educação e da 
escolarização como algo potencialmente benéfico, que se constituiu como verdadeira bandeira de luta assumida por diferentes sociedades. E Montes Claros não se eximiu destas discussões e preocupações, também elegendo a educação como remédio contra o atraso.

Os documentos acessados indicam que, em Montes Claros, a partir da década de 1920, as preocupações com a disciplina sofrem um deslocamento, em que a autoridade do professor assume outro lugar, influenciado por concepções escolanovistas. Neste contexto, classificamos o período anterior a 1920 e à modernização trazida pela Escola Nova, como um período de contraposição intuitiva à disciplina baseada em castigos, quando profissionais como Christina Vitalina dos Santos questiona essas práticas, sem se fundamentar em um discurso filosófico ou científico determinado.

A década de 1920, por sua vez, apresenta características de um período de transição, em que o discurso mineiro sobre a educação sofre transformações, por apropriações dos discursos e princípios defendidos pela Escola Nova.

\section{Autoridade e disciplina da década de 1920 - castigos e punições entre a tradição e a modernidade}

No Brasil, a década de 1920, representa um momento de transição entre as práticas ditas antigas e aquelas que representavam a renovação. Conforme De Lorenzo e Costa (1997), pesquisadores de diferentes campos das ciências sociais consideram a década de 1920 como a origem do Brasil Moderno. Para Granziera (1997), nesta década, a sociedade revela-se desafiadora e complexa, sendo que educação e instrução assumiram centralidade por, de certa forma, se constituírem como elementos que cimentavam e davam suporte às modificações pretendidas.

Em Montes Claros, na década de 1920, era intensa a preocupação dos educadores com a modernização, contexto em que se debate a disciplina das crianças e o papel dos pais na educação. Ao discutir a educação das crianças, o professor Polydoro Figueredo5 publica artigos em que afirma a necessidade de renovação, também apontando erros que os pais cometiam ao educar as crianças. A intenção do professor era produzir mudanças nas práticas educativas, demonstrar “(...) que a auctoridade e o respeito são, na educação, as duas maiores e mais santas coisas que apparecem como fundamento da obra que se trata de executar" (FIGUEREDO, 21 de dezembro de 1922, p.02).

Em 1923, Cícero Pereira ${ }^{6}$ considera que os pais precisavam assumir a educação

5 No ano de 1922, o Professor Polydoro Figueiredo (1864 - 1949) exercia a função diretor do Grupo Escolar
Gonçalves Chaves, também foi Inspetor Regional do Ensino na circunscrição de Montes Claros/MG e de
Grão Mogol/MG. Conforme Alberto Sena, Polydoro dos Reis Figueiredo era professor de Português no
Colégio Pedro II, no Rio de Janeiro. Natural de São Joaquim de Bicas, região metropolitana de Belo
Horizonte/MG, sagrou-se como um homem importante para o seu tempo, constituindo numerosa família
com 17 filhos, em dois casamentos. Disponível em <http://www.minaslivre.net/site/index.php/9-
uncategorised/2980-polidoro-figueiredo>. Acesso em: 11 de julho de 2016 .
6 Em 1923 , Cícero Pereira era diretor da Escola Normal da cidade de Montes Claros, então escola livre,
denominada Escola Normal Norte Mineira. Cicero Pereira (1881- 1948) nasceu no dia 14 de novembro, no
distrito de Grão Mogol, Zona de Diamantina/MG. Professor emérito, iniciou seus primeiros estudos em sua
cidade natal, aos 13 anos transferiu-se para Montes Claros a fim de melhor aproveitar os seus dotes
intelectuais, onde fez concurso para o magistério, ingressando na escola normal, onde recebeu o seu
diploma e lecionou por muitos anos. Disponível em <http://www.feig.org.br/index.php/nstituicao/nossos- 
dos filhos: "Seja o lar a sua primeira e mais importante escola: a escola em que os puros prazeres da vida limpa, e os exemplos do amor, da virtude, do trabalho, da harmonia" (PEREIRA, 1923a, p. 03). Na busca por mudar o quadro de desordem em que se encontravam os lares, o professor Cícero Pereira cria a "Liga dos Paes e Professores":

[...] destinada a promover a maior uniformidade possível na educação dos alumnos, pela approximação e conseqüente cooperação harmonica dos paes com os professores e os directores na consecução do alto desideratum do nosso ensino. (PEREIRA, 26 de maio de 1923b, p. 02).

No jornal Gazeta do Norte, Cicero Pereira conclama pais e professores, mas, sobretudo as mães de família, a unirem-se no esforço comum de proteger a infância e a mocidade. "A Liga dos Paes e Professores tem por fim o desenvolvimento das faculdades superiores do homem, cultivando com carinho o princípio de auctoridade, respeito, obediência e amor" (02 de junho de 1923c, p. 01). E, para atingir essa finalidade, "as reuniões serão inteiramente familiares, de modo a facilitar muito a conjugação de esforços, idéas e planos, tendentes todos a integrar na creança, no moço ou na moça, a mais perfeita educação physica, intellectual, moral e cívica" (PEREIRA, 26 de maio de 1923b, p. 02).

Nas defesas de Cícero Pereira, as crianças deveriam manifestar: "obediência prompta, completa, sem restrições"; em contrapartida, esperava-se que "a auctoridade do pae e da mãe seja inflexível, firme, doce e macia, como uma barra de ferro coberta de velludo" (PEREIRA, 26 de maio de 1923b, p. 02).

No entanto, em Montes Claros, por influência da sua Escola Normal e do movimento escolanovista, sobretudo, a partir de 1928, esses discursos sofrem deslocamentos, com severas críticas às práticas educativas ditas tradicionais. Conforme Veloso (2008), nas representações desta época, a modernidade pedagógica era compreendida como processo em que a civilização deixava de significar apenas urbanização da cidade, alfabetização e moralização da população. Era necessário que a educação produzisse o autogoverno, a autodisciplina e a liberdade da criança. Nesse quadro, a renovação da educação escolar e doméstica impôs-se. A mulher moderna deveria educar-se para educar as crianças, sendo salutar apropriar-se de conhecimentos científicos e tornar-se capaz de utilizar processos menos coercitivos e mais operativos para a obtenção do respeito e da disciplina. Liberdade e autodisciplina passam a ser vistos como traços característicos de uma educação moderna, não punitiva e não coercitiva, em que a aplicação de castigos passa a ser condenada como prática educativa, por constituir-se como desrespeito à criança e à sua individualidade (VELOSO, 2008).

Para a Escola Nova, o sujeito deveria aprender a controlar sentimentos e comportamentos por um processo de autorregulação e autocontrole, sem que fosse necessário utilizar castigos e punições. A educação nova se coloca como uma educação para a autonomia. Segundo Estrela (1992, p.21):

A formação do cidadão responsável, livre e participante na comunidade pressupõe uma educação em democracia. Por isso, a escola ideal, concebida como república de crianças, é a nova forma que permite o exercício da liberdade e da

mentores/139-prof-cicero-pereira>. Acesso em: 11 de julho de 2016. 
responsabilidade. A disciplina deixa de assentar na coerção externa para se transformar em autocontrolo e autogoverno.

Ainda segundo a autora, nas concepções desta época:

A manutenção da disciplina não exclui as sanções, mas a criança se submete a elas mais facilmente, porquanto contribuiu para a elaboração de regras e se sente responsável pela sua preservação. Não exclui também a intervenção do adulto que não se demite do seu papel de adulto. (ESTRELA, 1992, p.21)

No contexto mineiro, a partir da década de 1920, princípios da Escola Nova passam a influenciar as representações de autoridade e disciplina. A Revista do Ensino (1927) tece críticas às recompensas e castigos para disciplinar as crianças.

Encara-se o primeiro [recompensas] quase sem discussão, como recommendável. É grande erro pensar desse modo. Desde que se recompense immediatamente a creança por fazer o que deseja e se lhe permite, criar-se-lhe no espirito a falsa convicção de que a obediência tem por fim alcançar a recompensa. (REVISTA DO ENSINO, 23 de outubro de 1927, p.551)

Nas discussões da revista, o uso de recompensas era um equívoco, por não produzir efeitos duradouros. "Rapidamente, extingue-se o effeito da recompensa" (REVISTA DO ENSINO, 23 de outubro de 1927, p. 551) e as crianças retomam as práticas indesejáveis. Por sua vez, os castigos poderiam ferir os sentimentos e produzir uma reação negativa em relação aos pais e educadores.

O castigo corporal só deve, porém, ser applicado, mesmo em creanças sadias, enquanto a dôr constituir o principio activo. Quando as creanças atingem certa edade e se julgam feridas no amor próprio por castigos desta espécie, deve-se proscrel-os, pois, insistir nelles é fomentar rebeldia e ódio aos paes, ou educadores. (REVISTA DO ENSINO, 23 de outubro de 1927, p. 552)

Os castigos e recompensas eram inadequados para educar, por não produzirem a real mudança de comportamentos, não gerarem a autonomia e liberdade. Artigos escritos por Lúcio José dos Santos ${ }^{7}$ para a Revista do Ensino são ilustrativos do processo de apropriação de ideias, proposições e princípios que fundamentaram a renovação pretendida pela Escola Nova. Em matérias publicadas nas três primeiras edições da Revista do Ensino, em 1925, o autor faz uma síntese de conferência que houvera proferido em São Paulo, em que discute ideias de Rousseau e Kant, contrapondo autoridade e individualismo como elementos integrantes da educação (SANTOS, 1925a,

\footnotetext{
${ }^{7} \mathrm{Na}$ época da publicação destes artigos na Revista do Ensino, José Lúcio dos Santos (1875 - 1944) era Diretor da Instrução Pública de Minas Gerais. Dados publicados no site "UFMG - 80 ANOS", indicam que José Lúcio dos Santos nasceu em Cachoeira do Campo (MG), fez os primeiros estudos na terra natal, matriculou-se no Seminário de Mariana em 1888. Quatro anos depois, ingressou na Escola de Minas de Ouro Preto, onde se formou em Engenharia Civil e de Minas, sendo, posteriormente, professor naquela instituição. Lecionou também em vários estabelecimentos de ensino secundário de Minas Gerais. Em 1896, foi eleito vereador da Câmara Municipal de Ouro Preto. Diplomou-se em Direito na Universidade de São Paulo, em 1908. Em 1922, foi nomeado professor da Escola de Engenharia da Universidade de Minas Gerais (UMG), foi reitor da Universidade Federal de Minas Gerais (UFMG) entre março de 1931 a maio de 1933. Militou na imprensa e exerceu a direção de diversos órgãos públicos, como a Instrução Pública de Minas Gerais e a Escola de Aperfeiçoamento de Belo Horizonte. Autor de obras científicas importantes,José Lúcio dos Santos foi condecorado em diversos países. Disponível em <https://www.ufmg.br/80anos/reitores.html\#02>. Acesso em: 11 de julho de 2016.
} 
1925b, 1925c). Na segunda edição da revista, o professor afirma que, "não se pode haver boa educação sem autoridade: o systema de experiência pura, o systema individualista absoluto [em que a criança faz apenas o que deseja e nada lhe é imposto ou exigido], é absurdo e impraticável" (SANTOS, 14 de abril de 1925b, p. 36). Em sua argumentação, o professor discute ideias de Rousseau, que considerava o ato de educar com o sentido de respeitar a natureza da criança:

É preciso seguir a natureza diz Rousseau.

Mas que é seguir a natureza?

Não será certamente deixar que a creança faça tudo o que entender.

Ora, nesse caso, será indispensável uma auctoridade para dizer o que deva ser permitido, como natural, e o que deva ser prohibido, por anti-natural. (SANTOS, 14 de abril de 1925b, p. 37)

O professor afirma que Rousseau supunha a criança perfeita e boa, mas que poderia ser corrompida pela sociedade (SANTOS, 1925a). Ao citar Kant, José Lucio Santos afirma que este autor considerava a criança naturalmente má, tornando-se boa pela educação. No entanto, o professor não concordava com estes dois posicionamentos. Em sua opinião, tanto Rousseau como Kant estavam errados; era a pedagogia cristã que melhor esclarecia a questão, colocando a filosofia da criança longe dos excessos de Rousseau e de Kant. O professor entendia que determinadas disposições naturais da criança poderiam ser apenas orientadas, mas, em outras situações, era necessária autoridade:

A criança tem disposições naturaes que devem ser apenas cultivadas e desenvolvidas, estimuladas e orientadas, sem a autoridade, por uma cultura adequada. A criança manifesta tendências que precisam ser contrariadas ou apenas rectificadas, exigindo-se necessariamente a autoridade. (SANTOS, 8 de março de 1925a, p. 02)

Para o professor, o respeito aos direitos e à liberdade "é bonito de dizer-se. Mas, na criança, esses direitos se ignoram e essa liberdade está ainda em potência" (SANTOS, 10 de maio de $1925 \mathrm{c}$, p. 49). O professor não admite a possibilidade de se educar na ausência da autoridade do adulto - quer sejam pais ou professores. "A educação sem auctoridade é não só absurda em principio como impraticável de facto" (SANTOS, 10 de maio de $1925 \mathrm{c}$, p. 50). Em sua argumentação, considera que liberdade e disciplina precisavam estar integradas.

A disciplina e a liberdade não se excluem; completam-se.

A liberdade sem a disciplina é estéril e vã, quando não perigosa e anarchico.

A disciplina sem liberdade é servidão, e passividade; annulla a espontaneidade, mata a iniciativa; destroe ou falseia a responsabilidade. (SANTOS, 10 de maio de 1925c, p. 51)

Devemos atentar, entretanto, para a diferença que há entre aquilo que Rousseau e Kant pensavam e aquilo que José Lúcio dos Santos afirma sobre as concepções de tais autores. Rousseau e Kant são autores importantes no debate sobre autoridade, disciplina e liberdade, inclusive, no contexto em que surgiu a Escola Nova. Os dois representam, em geral, posições opostas nesse debate, mas mantém em comum, a contraposição às concepções arcaicas da tradição. 
Para Rousseau (2004) a autoridade estava associada à tradição, aos preconceitos que desconsideravam a natureza da criança - suas capacidades atuais e potencialidades -, impondo-Ihe, tanto conhecimentos além de sua compreensão, quanto uma disciplina impossível de ser seguida ou que degenerava o corpo (tornando-o fraco). Para ele, quando se ensina o que a criança ainda não pode aprender isso gera diversos problemas como a memorização vazia, o desprezo pelo conhecimento e a mentira (nas tentativas de se fingir saber o que não se sabe). De modo semelhante, quando se aplica uma disciplina impossível de ser seguida isso estimula a rebeldia e a trapaça. Assim, a educação baseada nessa autoridade era prejudicial ao desenvolvimento da criança. $O$ autor propunha, em vez disso, que a educação fosse baseada na observação da natureza da própria criança, que os ensinamentos e a disciplina deveriam ser conforme essa natureza. Para ele, a natureza humana era boa em si mesma - sendo corrompida pelos costumes e instituições sociais -, e a melhor educação era aquela que respeitava a natureza, sem tentar negá-la. Tal era a liberdade - a da natureza - que se contrapunha à autoridade preconceituosa da tradição. A liberdade, para ele, portanto, era seguir os caminhos da natureza, não era livre-arbítrio ou licenciosidade.

Para Kant, por outro lado, o homem a princípio não é naturalmente nem bom nem mau, ele é apenas amoral. Contudo, suas inclinações naturais o predispõem para o mau:

\footnotetext{
Pergunta: o homem é moralmente bom ou mau por natureza? Não é bom nem mau por natureza, porque não é um ser moral por natureza. Torna-se moral apenas quando eleva a sua razão até os conceitos do dever e da lei. Pode-se, entretanto, dizer que o homem traz em si tendências originárias para todos os vícios, pois tem inclinações e instintos que o impulsionam para um lado, enquanto sua razão o impulsiona para o contrário. (KANT, 1999, p. 95)
}

Na teoria kantiana há uma forte contraposição entre inclinação e dever. Inclinação é aquilo que a natureza nos leva a querer fazer, enquanto o dever é uma prescrição de conduta que impomos a nós mesmos quando seguimos a razão. Por exemplo, um homem que ajuda os necessitados porque sua inclinação o faz se sentir alegre com isso, não está sendo bom, está apenas se deixando guiar por sua natureza. Nesse caso, algum motivo egoísta está provavelmente associado a essa alegria/prazer, como gostar da demonstração de gratidão ou da admiração de outros. Para Kant, o dever possui outro estatuto, completamente distinto da natureza, que é o da razão. Somos bons quando fazemos o que o exercício da razão nos ditou como dever, independente de qualquer inclinação natural a favor ou contrária.

No debate entre autoridade e liberdade, Kant pende para a autoridade, mas essa já não é a autoridade da tradição (criticada por Rousseau), mas a autoridade da razão (universal), que transcende os homens individuais e a tradição. Ao mesmo tempo, Kant aproxima a liberdade dessa autoridade, pois, para ele, a verdadeira liberdade é agir em acordo com a razão. Quando seguimos nossas inclinações, não somos livres, mas sim escravos da nossa natureza.

Podemos dizer, então, que, para Rousseau, a principal autoridade a ser seguida na educação são as leis da natureza (não é a tradição) e ser livre é agir de acordo com essa natureza; e que, para Kant, a principal autoridade a ser seguida na educação são os imperativos da razão (novamente, não é a tradição), e ser livre é agir de acordo com a razão. Desse modo, ambos os autores retiram a autoridade da tradição e enfraquecem o 
papel do professor, enquanto representante da tradição, favorecendo o seu papel enquanto representante das ciências da natureza (no caso de Rousseau) e do espírito (no caso de Kant).

No tocante à disciplina, em Rousseau, esta consiste em expor sistematicamente a criança às limitações que a natureza lhe impõe e que a impelem a aprender, a se desenvolver, para superá-la:

É preciso que ela sinta a sua fraqueza e não que a sofra; é preciso que ela dependa, e não que obedeça; é preciso que ela peça, e não que mande. A criança só está submetida aos outros em razão de suas necessidades, e porque vêem melhor do que ela o que lhe é útil, o que pode contribuir ou prejudicar a sua conservação. Ninguém tem o direito, nem mesmo o pai, de ordenar à criança 0 que não lhe serve para nada. (ROUSSEAU, 2004, p. 81-82)

Em Kant, por outro lado, como a natureza em estado bruto é uma ameaça para a civilização, a disciplina se faz necessária para "transformar a animalidade em humanidade":

A disciplina submete o homem às leis da humanidade e começa a fazê-lo sentir a força das próprias leis. Mas isso deve acontecer bem cedo. Assim, as crianças são mandadas à escola, não para que aí aprendam alguma coisa, mas para aí se acostumarem a ficar sentadas tranquilamente e a obedecer pontualmente àquilo que Ihes é mandado, a fim de que no futuro elas não sigam de fato e imediatamente cada um dos seus caprichos. (KANT, 1999, p. 12)

Ambos os autores, entretanto, são contra a disciplina baseada em castigos. Em mais de uma passagem Rousseau relata castigos físicos como exemplo a não se seguir na educação das crianças:

Jamais esquecerei ter visto um desses incômodos chorões apanhar da ama-deleite. Calou-se de imediato; achei que ficara com medo. Dizia para mim mesmo: será uma alma servil de quem só se conseguirão as coisas através do rigor. Estava enganado: o infeliz sufocava de cólera, tinha perdido a respiração, vi-o tornar-se roxo. Logo em seguida vieram os gritos agudos [...] Se eu tivesse dúvida de que o sentimento do justo e do injusto é inato no coração do homem, só esse exemplo já me teria convencido. (ROUSSEAU, 2004, p. 54)

Kant também cita agressões físicas apenas como exemplo a não ser seguido. Diz que a educação rígida significa somente "afastar das comodidades", e que deve ser explicado à criança (quando ela tiver idade para entender), que o constrangimento da sua liberdade é para seu próprio benefício.

Discussões fundadas em Kant e Rousseau se fizeram presentes entre os educadores escolanovistas e foram captadas nas representações de educadores montesclarenses. Com Chartier (1990) é possível compreender que estas representações produzidas em Montes Claros constituem-se como práticas de ordenamento da sociedade, são historicamente produzidas e alimentadas pelos conteúdos que circulam no mundo social. Assim, com o autor, pode-se afirmar que as representações dos educadores montes-clarenses foram alimentadas pelos conteúdos em circulação naquele momento histórico. Em Montes Claros o debate sobre disciplina se intensificou na década de 1930, em especial nas defesas do professor José Raymundo Netto, que não reproduz um discurso dicotômico e simplista do pensamento de Rousseau e Kant, que discutimos 
na próxima seção.

\section{Autoridade e disciplina na década de 1930 - a ciência como fundamento para a negação dos castigos e punições}

Em Montes Claros, na década de 1930, encontramos um cenário diferente das questões propostas na década anterior, em especial nos escritos do professor José Raymundo Netto $^{8}$. Nestes, há a defesa de uma educação equilibrada nesse jogo entre autoridade e liberdade - e sem castigos físicos. Mas, essa defesa não é mais intuitiva, como a de Christina Vitalina dos Santos, na década de 1910; nem a autoridade rígida proposta por Cícero Pereira, na década de 1920; nem é a defesa filosófica em favor da tradição cristã, feita por José Lúcio dos Santos (este referente ao Estado de Minas, e não especificamente a Montes Claros, bom lembrar), também na década de 1920. Nos escritos do professor Raymundo Netto pode-se observar uma apropriação laica e, assim também, mais coerente, com os princípios da Escola Nova.

Ao discutir as dificuldades de se implantar os princípios da Escola Nova, o professor Raymundo Netto aponta o que considerava serem as três faces do problema da educação: 1) a iniciativa do aluno; 2) interesses infantis; 3) a sociabilidade e o trabalho com a comunidade (RAYMUNDO NETTO, 5 de maio de 1934a). Em relação ao primeiro problema, o professor aponta a necessidade de se reformar os métodos, criar um ambiente propício à aprendizagem, e “(...) não perder opportunidades uteis para o aproveitamento das actividades infantis, porquanto a criança tem em si um desejo inato de saber, uma curiosidade viva pelas cousas que a circundam" (RAYMUNDO NETTO, 16 de junho de 1934b, p. 02). O professor lembra que a atividade do menino é imanente, sendo que agir, fazer alguma cousa, é a lei que o domina e se equivale ao que o trabalho representa para o adulto.

Em relação ao segundo problema - os interesses infantis -, o professor lembra que este era o princípio básico da educação nova, que deveria constituir-se como educação funcional - capaz de produzir a atividade da criança, de forma que esta "queira com legítimo interesse fazer ou aprender aquilo que desejamos que ella faça ou aprenda, e esse legitimo interesse, acompanha sempre uma necessidade vital" (RAYMUNDO NETTO, 16 de junho de 1934b, p. 02).

O terceiro problema - sociabilidade e trabalho com a comunidade - era compreendido pela necessidade de vinculação entre o ensino e a vida social, sendo que o lema da Escola Nova era "aprender-vivendo e vivendo em sociedade" (RAYMUNDO NETTO, 16 de junho de 1934b, p. 02). Ao sinalizar a necessidade de educar para a vida, o professor propõe uma educação capaz de desvelar os perigos do mundo e preparar a

\footnotetext{
8 José Raymundo Netto (1897- 19??) foi um ilustre educador, nascido em Carangola/MG. De acordo com Nelson Viana (2011), ele fez o curso primário em Januária e o secundário em Paracatu. Exerceu a advocacia civil e criminal em Januária, onde foi professor da Escola Noturna. Fundou, dirigiu e foi professor de Português, Geografia, História e Ciências no Ginásio de Três Corações, Sul de Minas, de 1931 a 1933. Foi Diretor do Grupo Escolar de Espinosa (Disponível em: <http://montesclaros.com/n/mural.asp?pg=578>. Acesso em: 11 de julho de 2016. Publicação n 5 69258 , em 11/10/2011, 07:26:39). Em Montes Claros, exerceu a função de professor de Psicologia, Metodologia e Prática Profissional e de diretor da Escola Normal Official de Montes Claros entre 1935 e 22 de janeiro de 1938, data em que a escola foi suprimida por Decreto Lei n. 63, do governo mineiro. Após o fechamento da Escola Normal, Raymundo Neto exerceu a função de professor de Psicologia do Colégio Imaculada Conceição de Montes Claros.
} 
criança para agir e se defender.

Na Revista do Ensino, no ano de 1933, Manoel Casasanta também discute a necessidade de orientar a criança para adaptar-se ao mundo social, cabendo à escola instruir e educar. Contudo, instruir não era a finalidade principal da escola, mas uma de suas finalidades. "A escola, que é a própria vida, objetiva munir a criança de técnicas que Ihe assegurem perfeita adaptação ao meio em que vive, de futuro, exercitará sua atividade" (01 de fevereiro de 1933, p. 09), de forma autônoma, independente de controle externo. E, como na vida social não há prêmios, Manoel Casasanta condena as premiações como forma de educar a criança e obter o seu bom comportamento.

O próprio professor Raymundo Netto, na década de 1930, publicou artigos na Revista do Ensino, em que condena a aplicação de castigos, apesar de constatar que sua prática era muito comum entre pais e professores.

Os castigos, de qualquer espécie que sejam, estão inteiramente condemnados: deprimem o sentimento e, uma vez adoptados, exigem applicação cada vez mais rigorosa para que possam produzir effeito.

Exemplo: castiga-se hoje uma criança por determinada falta. Amanha, si a creança commete a mesma falta, o mesmo castigo será inefficiente; torna-se necessário o emprego de uma penalidade mais severa e, assim, o educador prossegue numa gradação perigosíssima para a obra que deseja realizar. (RAYMUNDO NETO, abril de 1930, p. 05)

Em 1933, citando Julio Porto Carrero, o professor Raymundo Netto diz que, a educação doméstica tal qual a temos, é a verdadeira "arte de perverter" (maio a agosto de 1933, p. 38). Raymundo Netto reconhece o peso da afirmação, mas considera que esta é "uma verdade inconteste aos que pensam e observam". Em sua argumentação, todo educador, mesmo inconscientemente, tem um princípio ou uma concepção filosófica de vida e de educação, que orienta os processos educativos e a sua prática cotidiana. Assim, antes de tomar uma atitude perante os educandos, os professores fazem escolhas.

E, infelizmente, o ponto de vista geralmente aceito é o da coerção: - é preciso contrariar a criança, reprimir seus impulsos instintivos, castigá-la mesmo, para que se torne possível sua formação moral de acôrdo com os cânones atuais da civilização.

A educação pelo medo e pelos castigos, eis o que se pratica geralmente em nosso meio. (RAYMUNDO NETO, maio a agosto de 1933, p. 39)

Em suas críticas, Raymundo Netto questiona a crença de que a criança não poderia fazer nada independente do auxílio dos adultos e condena os sentimentalismos na educação da infância.

Os sentimentalismos piegas, histórias piedosas e fantasistas; os assumptos mysticos, que fazem depender a felicidade de todo o macabro de Morte e da Vida de além-tumulo, de todos os horrores da punição e do pecado e de todos os sacrifícios da renuncia, acabam por cultivar a angustia da creança, tolhendo-lhe ainda mais a iniciativa e fazendo-a aguardar o bom êxito da vida, da parte do maravilhoso, do sobre-natural.

Educar não é occultar o perigo: é ensinar a defesa ante o perigo. Educar não é amedrontar, cultivar a angustia: - é ensinar a acção, que deve contravir às agressões do meio. (RAYMUNDO NETTO, 11 de agosto de 1934c, p. 02)

Para José Raymundo Netto, a educação deveria orientar a criança para a vida 
social, não lhe impondo medos para discipliná-la, mas, também, não a deixando entregue aos seus instintos. Era necessária autoridade do adulto em relação à criança, sem violência, sem imposição de normas, valores e comportamentos, sem aplicação de castigos.

\begin{abstract}
A Escola Nova, quanto à concepção philosophica acerca da criança, não está com os extremistas: $=$ nem com os que a consideram como naturalmente má e só educável pelos meios coercitivos, nem com aquelles que julgam conveniente abandonal-a à sua própria Natureza para a consecução de um pleno e harmonioso desenvolvimento. Não, a natureza do homem tende naturalmente para a ordem, a disciplina, o methodo, o governo de si mesmo, mas não marcha fatalmente para esses fins, tão almejados pela Civilização.

É necessário que em torno à criança, se forme um ambiente rico de estímulos aptos a favorecer o pleno desenvolvimento de todos os poderes superiores de seu espirito.

E é esse ideal máximo da escola nova ou educação progressiva: - levar o educando, pela acção querida e vivida, a aquisição das mais altas virtudes sociaes: - coragem, paciência, lealdade, espirito de sacrifício, amor ao próximo, disciplina ou auto-governo!

É preciso portanto que, no ideário da Escola Nova, seja bem comprehendido por todos os educadores o principio cardeal que a orienta: - Liberdade e respeito à individualidade da criança! (RAYMUNDO NETTO, 11 de agosto de 1934c, p. 02 destaques no original)
\end{abstract}

Observa-se, nesse trecho, o que poderia ser uma dicotomização simplista do pensamento de Rousseau e Kant. Raymundo Netto, porém, não o faz para defender a tradição religiosa, como José Lúcio dos Santos, mas para avançar no espírito do lluminismo: liberdade, individualidade, autogoverno etc. E, portanto, está no mesmo caminho de Rousseau e Kant.

Ainda conforme Raymundo Netto, o objetivo principal da educação era a conquista da liberdade e o respeito à individualidade da criança, não a deixando entregue aos seus instintos, mas ensinando-a a viver em grupo e a conviver com os outros.

Si deixarmos a criança entregue à sua própria natureza, à sua pura espontaneidade, tornar-se-á ella um ser caprichoso, rebelde = com prejuízo do caráter; si a submetermos a um regimem de lei, imposta à viva força, formaremos um individuo de caráter servil, escravizado e que nunca se bastará a si mesmo.

Como agiremos então? Não haverá um terceiro termo em que lei e espontaneidade se combinem; em que a espontaneidade se estructure em lei? (RAYMUNDO NETTO, 18 de agosto de 1934d, p. 01)

Por esta lógica, o professor alerta para dois equívocos. De um lado, quando pais e professores se orientavam pela velha educação, ignorando a força dinâmica e evolutiva inerente à experiência da criança, adotavam o controle, a direção e a coação para forçar a criança para um determinado caminho. Por outro lado, havia a não diretividade, inserida no seio da Escola Nova, em que "espera-se do menino que elle desenvolva de seu espirito tal qualidade ou tal facto por si mesmo!" (RAYMUNDO NETTO, 18 de agosto de 1934d, p. 01).

Para Raymundo Netto (1934d), o educador sensato deveria posicionar-se entre estes dois extremos, nem dar liberdade excessiva à criança, nem agir pela coação e imposição. 
Deixar a criança entregue a si mesma, obedecer excessivamente à vontade da criança, é comprometer a obra da sua formação integral e harmoniosa; usar de rigor, severidade, insultos e castigos, pôr em prática, enfim os processos de Recalcamento na obra de sua educação, é prejudica-la profundamente. (RAYMUNDO NETTO, 18 de agosto de 1934d, p. 01 - itálico no original)

No uso que Raymundo Netto faz dos conceitos de recalcamento e sublimação, encontramos a influência do trabalho de Sigmund Freud (1856-1939). Para o inventor da Psicanálise, o recalcamento (Verdrängung, em alemão, também traduzido por "repressão") é o mecanismo de defesa que rejeita determinadas representações no consciente, enviando-as para o inconsciente. Esse processo, portanto, ainda que mantenha a representação inaceitável longe da consciência, não elimina uma parte do instinto (Trieb, em alemão, também traduzido por "pulsão"), que continua agindo do inconsciente, e produz, dentre outras coisas, sintomas indesejados, pois "ele [o instinto] prolifera no escuro, por assim dizer, e assume formas extremas de expressão" (FREUD, 1996a, p. 154). Como vimos, Raymundo Netto sabia dos perigos desse recalcamento dos instintos feito por meio de "rigor, severidade, insultos e castigos", pois esses processos disciplinares não eram formadores, apenas deslocavam os impulsos indesejados de lugar e adiavam momentaneamente sua expressão.

Já a sublimação, por sua vez, seria um dos destinos possíveis do instinto, que, em vez de recalcado, é desviado para objetos socialmente aceitáveis da cultura, como a religião, as artes, os esportes e a ciência (FREUD, 1996b).

Ao posicionar-se contrariamente ao recalcamento, o professor Raymundo Netto considera que a escola deveria canalizar as energias da criança pela realização de atividades artísticas e pelo contato com a natureza, em acordo com o conceito freudiano de "sublimação":

Sublimar, ao envez de recalcar. A arte, na família, na escola e na sociedade é a estrada larga para todas as sublimações: - o canto, o theatro, canções populares, jogos, brinquedos, musica, esporte, desenho, modelagem, jardinagem, trabalhos manuais, construção, declamação, bailes, emfim, o culto da Natureza e de tudo o que é bello e sublime!... (RAYMUNDO NETTO, 18 de agosto de 1934d, p. 01 itálico no original)

Ao discutir os princípios da Escola Nova, Lourenço Filho (1978) afirma que, pelo controle dos comportamentos instintivos, "a pessoa substitui o alvo de seus motivos, empenhando-se então a fundo numa atividade compensadora". Para o autor, era necessário ajustar o comportamento das crianças por meio de substituições das atitudes e práticas indesejadas por outras que representassem maneiras socialmente úteis. E lembra, "as substituições, que envolvem elevado nível de apreciação social ou moral, dáse o nome particular de sublimação" (1978, p. 112).

Assim, se fazia necessário criar um ambiente rico em estímulos, para educar a criança com liberdade e respeito à sua individualidade, com tolerância para com os seus erros, evitando-se o uso da força.

Quando defronta um querer, que lucta contra o seu próprio querer, surge nella o desejo de superar o querer alheio. Trava-se então um duello, em que se vencerá o educador ou a criança. É preciso evitar esta situação de lucta, que dá a sensação de um choque entre duas vontades! 
Levar a criança pelo raciocínio: uma reprehensão a frio vale muito mais do que as explosões coléricas do educador.

Nos momentos difficeis procurar penetrar no mundo emotivo da criança, leval-a a querer o que o educador deseja que ella queira. (RAYMUNDO NETTO, 18 de agosto de 1934d, p. 01)

Nos posicionamentos do professor, vislumbra-se a tradição iluminista, por uma apropriação consistente do discurso científico da Escola Nova e da Psicanálise. Com Raymundo Netto podemos ver que, na década de 1930, Montes Claros se afina, enfim, com o pensamento moderno em favor de uma escola não autoritária, não violenta e promotora da autonomia no estudante.

\section{Considerações finais}

Neste artigo, produzimos visibilidade para a questão disciplinar a partir de representações disseminadas em Montes Claros, entre as décadas de 1910-30. Ao apresentar e discutir tais representações, não nos orientamos pelo sentido de revelar a "verdade" sobre a temática. Isso porque as representações podem ser, ao mesmo tempo, ilusórias, contraditórias e "verdadeiras", podendo expressar crenças, valores, sentimentos e expectativas. E, no espaço-tempo em que mapeamos as representações dos educadores, a disciplina foi compreendida como condição para produzir a civilização e integrar a cidade de Montes Claros no contexto das metrópoles desenvolvidas e modernas.

Em nosso estudo, percebemos deslocamentos nas representações. Inicialmente, na década de 1910, encontram-se processos disciplinares orientados pela lógica da aplicação de castigos e punições em contraposição a discursos que, intuitivamente, negam essas práticas. Na década de 1920, os discursos apontam a necessária autoridade dos pais - modelos a serem seguidos pelas novas gerações. Apontam, ainda, a necessidade de revisão das concepções e práticas, no lar e na escola, de forma a romper com os castigos e a violência, a falta de afeto na relação adulto-criança. Era claro o posicionamento em favor da autoridade paterna, mas o espírito de modernidade e de civilização considerava inaceitáveis as práticas impostas, violentas, desprovidas de afeto e calor humano.

A década de 1920, por sua vez, apresenta características de um período de transição. Vemos uma transformação no discurso mineiro sobre a educação, no que tange aos temas da autoridade, da disciplina e da liberdade, com uma absorção, ainda que ambígua, do discurso filosófico e científico produzido desde o final do século XVIII, na Europa, sobre esses temas. Ambígua, porque, ao mesmo tempo em que se pode observar a defesa de algumas das inovações trazidas por tais discursos - dos quais podemos citar, por exemplo, as filosofias de Rousseau e de Kant, pode-se observar, também, uma resistência a aderir a esses discursos naquilo que eles tinham de mais disruptivo em relação a alguns aspectos da tradição, em especial, os relacionados à religião católica.

Nesse período, nos artigos da Revista do Ensino, percebemos um processo de apropriação que sinalizam para simplificações das ideias de Rousseau e Kant. Isso porque, diferentemente do que afirma José Lúcio dos Santos, para Rousseau, à criança não é permitido fazer o que bem entender. Nem foi proposta de Kant o extremo oposto 
desse Rousseau fantasiado, isto é, em que se pode supor uma educação que fosse apenas submissão inconteste. Em ambos os autores os adultos têm um papel essencial e diretivo, quer no sentido de não perturbar a natureza da criança com os vícios da civilização (Rousseau), quer no sentido de conduzir a natureza da criança à cultura (Kant). Porém, a autoridade dos adultos está submetida a outra autoridade: as leis da natureza (Rousseau) ou os preceitos da razão (Kant), e não aos preceitos religiosos, que José Lúcio defendia.

Observa-se, assim, nos artigos de Lúcio José dos Santos, de um lado, a absorção de inovações trazidas pelo discurso moderno sobre a autoridade, a disciplina e a liberdade, porém, por outro lado, observa-se uma simplificação das ideais de Rousseau e Kant, as quais, se levadas em conta de modo mais aprofundado, entrariam em conflito direto com a tradição religiosa defendida pelo autor.

Por fim, a década de 1930 é um período em que explodem os discursos em favor da renovação inscrita na Escola Nova, em que a criança é compreendida a partir de seu ponto de vista - suas possibilidades e limitações em cada momento - e não a partir do ponto de vista adulto. Neste sentido, a disciplina escolar não se baseia mais na autoridade (paterna ou religiosa) e passa a buscar na ciência as bases para sua atuação. Raymundo Netto, como vimos, foi um caso exemplar, no qual se pode observar de forma bastante consistente a presença da modernidade filosófica e científica sobre a educação em Montes Claros.

Para encerrar, podemos levantar alguns questionamentos inspirados pela obra de Michel Foucault, a título de provocação, já que neste artigo não foi nosso foco fazer uma análise exaustiva a partir dos conceitos desse autor. Como explicitamos anteriormente, Foucault se preocupou com o tema da disciplina não como um conjunto de normas passado de cima para baixo por uma instituição detentora do poder, mas a entendia como um jogo de forças atuando por meio de muitos mecanismos e em diversos sentidos, inclusive conflitantes, e perpassando a família, a escola, a prisão, o hospital, a religião, a filosofia, a ciência, a política e assim por diante. Em outros trabalhos, como, por exemplo, Foucault (2003), o autor chama a atenção para uma característica muito importante de exercício e manifestação do poder, que é a ação sobre si mesmo. Tratando sobre a "moral" ele diz que "toda ação moral comporta uma relação ao real em que se efetua, e uma reação ao código a que se refere" e acrescenta que ela implica, igualmente, certa relação a si, que não significa apenas uma "consciência de si", mas constituição de si enquanto "sujeito moral", na qual delimita a parte dele mesmo que é objeto dessa prática moral. Assim, o sujeito "define sua posição em relação ao preceito que respeita, estabelece para si um certo modo de ser que valerá como realização moral dele mesmo; e, para tal, age sobre si mesmo, procura conhecer-se, controla-se, põe-se à prova, aperfeiçoa-se, transforma-se" (FOUCAULT, 2003, p. 28).

Para Foucault, quem quiser fazer uma história da moral terá que, dentre outras coisas, fazer uma "história da maneira pela qual os indivíduos são chamados a se constituir como sujeitos de conduta moral" (2003, p.29). Esse âmbito do exercício do poder é o que ele chamará em outros trabalhos de governo de si. A provocação que fazemos - a nós mesmos, e aos nossos leitores -, com base nisso, é a seguinte: observamos nas representações de professores em Minas Gerais, especialmente em Montes Claros, de 1910 a 1930 uma transformação da disciplina, de uma contraposição 
intuitiva à disciplina baseada em castigos e orientada pela autoridade tradicional para uma disciplina não violenta, menos coercitiva, embasada pelo discurso iluminista dos séculos XVIII e XIX e pelo discurso propriamente científico do século XX. Entretanto, se atentarmos para esse âmbito do governo de si, podemos nos perguntar, será que essa autonomia, o "governo de si mesmo" ou "auto-governo" - expressões que aparecem assim, a propósito, em um dos textos de Raymundo Netto anteriormente citados - são realmente manifestações de uma maior liberdade, como pretendiam Rousseau, Kant e os outros iluministas e mesmo os pensadores da Escola Nova ou são apenas diferentes estratégias de poder? Essa nova concepção de disciplina significou realmente uma abertura em relação às normas e aos padrões tradicionais, ou significou mais uma transformação sobre a forma como a norma se impõe, agora mais rigorosamente de dentro para fora do que antes?

\section{Referências}

CHARTIER, Roger. À beira da falésia: história entre certezas e inquietudes. Porto Alegre: Editora da Universidade/UFRGS, 2002.

. História Cultural: entre práticas e representações. Trad. Maria Manuela Galhardo. Rio de Janeiro: Berthand do Brasil, 1990.

CUNHA, Marcos Vinícius da. A escola contra a família. In: LOPES, Eliane Marta Teixeira; FARIA FILHO, Luciano Mendes; VEIGA, Cyntia Greive (Orgs). 500 anos de educação no Brasil. Belo Horizonte: Autêntica, 2003. p.447-468.

ESTRELA, Maria Teresa. Relação pedagógica, disciplina e indisciplina na aula. Porto: Porto Editora, 1992.

FOUCAULT, Michel. Vigiar e punir: nascimento da prisão. 42. ed. $2^{\underline{a}}$ reimp. Petrópolis, RJ: Vozes, 2014.

. História da sexualidade 2; o uso dos prazeres.10. ed. Rio de Janeiro: Edições $\overline{\text { Graal, }} 2003$.

FREUD, Sigmund. Os instintos e suas vicissitudes. In: . Obras psicológicas completas de Sigmund Freud: edição standard brasileira (Volume XIV). Rio de Janeiro: Imago, 1996a.

. O mal-estar na civilização. In: . Obras psicológicas completas de Sigmund

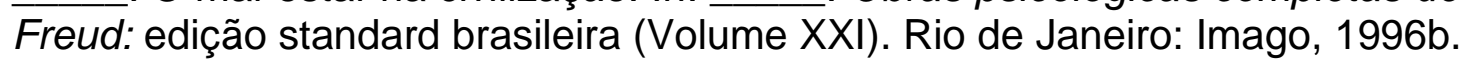

GADOTTI, Moacir. História das ideias pedagógicas. 5. ed. São Paulo: Ática, 1997.

GRANZIERA, Rui Guilherme. O Brasil depois da Grande Guerra. In.: DE LORENZO, Helena Carvalho; COSTA, Wilma Peres da (Orgs.). A década de 20 e as origens do Brasil moderno. São Paulo: Editora da UNESP, 1997. p. 135-142.

KANT, Immanuel. Sobre a Pedagogia. Piracicaba: Editora Unimep, 1999.

LIBÂNEO, José Carlos. Didática. São Paulo: Cortez, 1994.

LOURENÇO FILHO, Manoel Bergstrom. Introdução ao estudo da escola nova: bases, sistemas e diretrizes da Pedagogia contemporânea. 12. ed. São Paulo: Melhoramentos; Rio de Janeiro: Fundação Nacional de Material Escolar, 1978.

MIZUKAMI, Maria das Graças Nicoletti. Ensino: as abordagens do processo. São Paulo: EPE, 1986.

ROUSSEAU, Jean-Jacques. Emílio - ou da Educação. São Paulo: Martins Fontes, 2004. 
VELOSO, Geisa Magela. A missão desanalfabetizadora do jornal Gazeta do Norte em Montes Claros (1818-1938). 2008. Tese (Doutorado em Educação) - Faculdade de Educação da Universidade Federal de Minas Gerais, Belo Horizonte, 2008.

\section{Fontes documentais}

CASASANTA, Manuel. Os prêmios na escola. Revista do Ensino, Órgam Official da Inspetoria da instrução, Belo Horizonte, Ano VII, n. 81, 1ํ fevereiro de 1933.

FIGUEREDO, Polydoro. A criança. Jornal A ordem, Montes Claros, ano 01, n. 03, 21 de dezembro de 1922.

GAZETA DO NORTE. Escola Normal Official de Montes Claros: sua organisação no corrente anno - o problema de educação da mocidade feminina. Montes Claros: Gazeta do Norte: semanário literário e independente. Ano XVII, n. 957, 30 de março de 1935.

PEREIRA, Cícero. A Educação e a Atmosphera Moral do Lar. Gazeta do Norte, Ano V, no 260, 14 de julho de 1923a.

. Escola Normal. Liga dos Paes e Professores. Gazeta do Norte, Ano V, n. 253, 26 de maio de 1923b.

. Liga dos Paes e Professores - Sua grande importância. Gazeta do Norte, Ano V. n. 254, 02 de junho de 1923b.

RAYMUNDO NETTO, José. Escola Activa - liberdade e disciplina. Revista do Ensino: Órgam Official da Inspetoria da instrução, Belo Horizonte, Ano V, n. 44, Abril de 1930.

. Na Escola Normal Official: Montes Claros. Gazeta do Norte: semanário literário e independente, Ano XVII, n. 926, 18 de agosto de 1934 (1934d).

. Pela instrucção. Escola Normal Official. Gazeta do Norte: semanário literário e independente, Montes Claros, Ano XVII, n. 925, 11 de agosto de 1934 (1934c).

. Problema de educação. Revista do Ensino: Órgam Official da Inspetoria da instrução, Belo Horizonte, Ano VII, n. 87-88, Maio a Agosto de 1933.

. Treis phases da pedagogia. Gazeta do Norte: semanário literário e independente, Montes Claros, Ano XVI, no 912, 05 de maio de 1934 (1934a).

.Pela instrucção. Escola Normal Official. Gazeta do Norte: semanário literário e independente, Montes Claros, Ano XVII, no 918, 16 de junho de 1934 (1934b).

REVISTA DO ENSINO. Disciplina da creança - Recompensa e castigo - Problema do castigo corporal. Revista do Ensino: Orgam Official da Inspectoria da Instrucção, Belo Horizonte, Ano III, n. 23, Outubro de 1927.

SANTOS, Christina Vitalina dos. Correspondência de Christina Vitalina Santos ao Secretário do Interior do Estado de Minas Gerais. SI 3440. 24 de abril de 1913.

SANTOS, José Lucio. O individualismo e a autoridade em educação - trechos de uma conferência realizada em São Paulo. Revista do Ensino: Orgam Official da Inspectoria da Instrucção, Belo Horizonte, Ano I, n. 01, 08 de março de 1925 (1925a).

SANTOS, José Lucio. O individualismo e a autoridade em educação. Revista do Ensino: Orgam Official da Inspectoria da Instrucção, Belo Horizonte, Ano I, n. 02, 14 de abril de 1925 (1925b).

SANTOS, José Lucio. O individualismo e a autoridade em educação. Revista do Ensino: Orgam Official da Inspectoria da Instrucção, Belo Horizonte, Ano I, n. 10, 10 de maio de 1925 (1925c). 
SOUSA, Herculino Pereira de. O meu último relatório. SI 3473. Inspectores municipaes relatórios. 6⿳亠丷厂 secção. 30 de janeiro de 1914.

Horas Vagas. Jornal Montes Claros, Ano I, n. 26, Montes Claros - Minas Gerais, 26 de outubro de 1916. 1916a/ Publicação Semanal.

Horas Vagas. Jornal Montes Claros, Ano I., n. 30, Montes Claros - Minas Gerais, 30 de novembro de 1916. 1916b/ Publicação Semanal.

GEISA MAGELA VELOSO é professora da Universidade Estadual de Montes Claros/Unimontes; Doutora em Educação pela Universidade Federal de Minas Gerais/UFMG.

Endereço: Rua Prof. João Câmara, 651 - 39401.351 - Montes Claros/MG - Brasil

Email: velosogeisa@gmail.com

RAFAEL BAIONI DO NASCIMENTO é professor da Universidade Estadual de Montes Claros/Unimontes; Doutor em Psicologia Escolar e do Desenvolvimento Humano pela Universidade de São Paulo/USP.

Endereço: Rua Aloísio Ferreira Pinto, 200 - 39401.094 - Montes Claros/MG - Brasil

E-mail: baionirafael@gmail.com

MÔNICA MARIA TEIXEIRA AMORIM é professora da Universidade Estadual de Montes Claros/Unimontes; Doutora em Educação pela Universidade Federal de Minas Gerais/UFMG.

Endereço: Rua Dr. Henrique Chaves, 444 - 39403.440 - Montes Claros/MG - Brasil

Email: monicamorimsa@hotmail.com

Recebido em 16 de setembro de 2016.

Aceito em 31 de outubro de 2016. 